\title{
Le stéthoscope et la souris : savoirs médicaux et imaginaires numériques du corps
}

\author{
Antonio A. Casilli*
}

$\mathbf{P}_{\text {endant longtemps, la méfiance de la profession médicale vis-à-vis }}$ des nouvelles technologies informatiques a été un fait avéré. Dans les années 1980 encore, le lancement du réseau télématique canadien MediLink est salué par la presse comme un échec annoncé:

La plupart des docteurs sont des analphabètes en informatique [...]. Plus de $70 \%$ des médecins généralistes n'ont pas d'ordinateurs dans leurs cabinets ${ }^{1}$.

En Europe, les fiches informatisées ne sont utilisées que par un médecin sur sept. Les praticiens anglais poussent leur opposition à l'informatisation jusqu'à refuser l'offre promotionnelle d'ordinateurs gratuits ${ }^{2}$.

Il ne s'agit pas d'un simple effet d'inertie professionnelle: le monde de la médecine et celui des nouvelles technologies se veulent porteurs de deux visions complètement différentes du corps. D'une part, le corps tangible du patient - une anatomie parcourue par des flux, des battements, des symptômes inquiétants qui attestent de la nécessité de l'intervention réparatrice du thérapeute. De l'autre, la vie réduite à un jeu d'octets, le corps rêvé par les informaticiens amateurs - une forme virtuelle qui vit en symbiose avec les écrans d'ordinateurs, qui s'autorise une existence consacrée aux jeux et aux rencontres.

Il est pour le moins inattendu de constater à quel point, à peine une décennie plus tard, la situation a radicalement changé. Déjà à la

* Sociologue, chercheur, associé au Centre Edgar Morin (CNRS, Paris). Il prépare un ouvrage sur les sociabilités numériques à paraître au Seuil.

1. Tamsin Carlisle, "Diagnosing Data-Processing Disease", The Financial Post, 28 juillet 1989.

2. Caroline Berman, "Doctoring the Data", The Guardian, 6 août 1987. 
fin des années 1990, les médecins américains ne jurent plus que par la «santé électronique» $\left(e-H e a l t h^{3}\right)$. Dans les cabinets des généralistes français, «le tensiomètre voisine avec le modem, les abaisselangues avec l'imprimante ${ }^{4}$ ».

Certes, la profession médicale a suivi un mouvement général vers l'informatisation - en cela elle ne diffère pas d'autres métiers. Mais l'intégration des nouveaux médias électroniques dans la pratique clinique et dans la recherche médicale relève d'un syncrétisme culturel plus foncier. Aujourd'hui, les simulations 3D sont utilisées dans l'apprentissage de l'anatomie ainsi que dans la conception de nouveaux médicaments. La chirurgie s'appuie de plus en plus sur la robotique et sur la téléprésence. La génétique ne doit ses triomphes qu'aux nouvelles démarches de la biologie computationnelle. Nous sommes face à un syncrétisme culturel, qui sous-entend la confluence d'usages et de visions du corps jusque-là séparés.

Il faut, pour rendre compte de ce changement, emprunter un chemin oblique. Ce n'est pas du côté de la médecine, mais de celui des nouvelles technologies qu'on doit rechercher les causes historiques de l'alliance inattendue entre la pratique médicale et l'imaginaire numérique du corps - entre le stéthoscope et la souris. C'est entre 1983 et 2001, au sein de la culture des usagers des ordinateurs et des réseaux numériques, qu'a lieu ce glissement profond de notre sensibilité culturelle: la question du corps devient indissociable de celle des technologies. Le magazine canadien Adbusters résume ce mythe moderne dans les termes suivants:

Branchez-vous à un ordinateur et votre corps s'évanouira de l'espace de la matière charnelle pour surgir dans un monde plus vaste - dans l'étendue numérique du cyberespace ${ }^{5}$.

La technologie transfigure-t-elle, exalte-t-elle la corporéité? Le corps, paraît-il, s'échappe de son contexte matériel pour être inscrit dans l'espace même de l'information. Il est arraché à sa dimension bio-organique.

Mais le mythe du corps digitalisé, magnifié par les technologies informatiques doit être lu comme une stratégie culturelle. Il traduit une préoccupation croissante, au sein de nos sociétés, vis-à-vis de la santé et du bien-être. Il traduit tout autant une méfiance envers le domaine médical, répandue à la fin du $\mathrm{XX}^{\mathrm{e}}$ siècle. Les protagonistes de la soi-disant «révolution numérique» ont voulu ébranler certaines des certitudes acquises de la recherche scientifique et de la pratique

3. Helga Rippen et Ahmad Risk, "The Washington Code of e-Health Ethics and Other Ethical Codes", Journal of Medical Internet Research, vol. 2, n 2, 2000, e9, www.jmir.org/2000/2/ e9/ [dernier accès 22 mai 2008].

4. Gérard Pangon, «François-Xavier Callies, médecin», Télérama, hors série "Internet et moi, et moi et nous ", 1999.

5. "Cyborg Manifesto", Adbusters, no 34, suppl. 1, mars-avril 2001. 
clinique. Face à la montée de nouvelles épidémies et de risques sanitaires globaux, rêver d'un corps numérisé signifie, pour des milliards d'usagers, soustraire ce même corps à l'emprise d'institutions savantes qui se révèlent incapables de le protéger.

\section{L'alarme sida et la «désobéissance civile électronique»}

L'essor de la micro-informatique populaire des années 1980 marque la naissance de la culture numérique d'aujourd'hui. Les machines à calculer, qui dans l'après-guerre avaient été du ressort d'ingénieurs et de technocrates, deviennent à ce moment les outils de choix d'une multitude de collectivités issues de la société civile internationale. Inspirés par des principes libertaires et égalitaires, les jeunes japonais passionnés de jeux vidéo et les premiers adeptes du minitel se rallient aux pirates télématiques européens ou aux techniciens hippies de la Silicon Valley. Le mot clé, dans cette phase, est «autonomie»- autonomie des usages sociaux des calculateurs électroniques, qui quittent les laboratoires militaires et les grands établissements industriels pour s'installer dans les maisons des particuliers. Domestiquées, les machines se transforment en home computers. Humanisées, elles deviennent des personal computers.

Les imaginaires sociaux commencent à rendre compte de ce changement. "L'ordinateur s'installe dans le foyer», annonce le Time du 3 janvier 1983. À la une, un homme assis semble dialoguer avec un micro-ordinateur. Mais le dialogue se fait ambivalence entre physionomie humaine et forme technologique quand on lit que le titre d' "homme de l'année », traditionnellement décerné par le magazine américain à l'occasion de la première livraison de janvier, est désormais attribué à la «machine de l'année ${ }^{6}$ ».

La chair et le chiffre évoluent déjà sur le même plan figuratif. De même, les campagnes publicitaires pour les micro-ordinateurs n'insistent plus sur la précision ni sur le rendement des puces électroniques. Elles renvoient des images de beauté, de loisir, de performance corporelle. L'informaticien n'est plus en blouse blanche, mais en combinaison de sport, en collants de gymnastique, en maillot de bain.

Le spot 1984 pour l'ordinateur MacIntosh d'Apple est peut-être l'exemple le plus remarquable de cette iconographie. Dans un camp de concentration orwellien, des prisonniers marchent en cadence. Leurs pas lourds et leurs apparences maladives contrastent avec les propos d'un Big Brother qui, d'un écran géant, vante les bienfaits de la «Directive de purification de l'information» visant à «assainir les

6. Otto Friedrich, "Machine of the Year: The Computer Moves In", Time, vol. 121, n 1, 3 janvier 1983. 
cellules de l'État». Habillée en joggeuse et brandissant un marteau, une jeune femme surgit. Elle incarne le personal computer, qui accomplit le geste libérateur: le marteau est projeté énergiquement contre l'écran, qui explose dans un éclat de lumière. Une bouffée d'air frais fait finalement revivre les détenus ${ }^{7}$.

Le binôme ordinateur/renouveau du corps se trouve ici énoncé d'une façon claire. Ailleurs, les usages informatiques sont associés d'une manière grandissante à l'entretien de la santé, ainsi qu'à une ambition de perfectibilité physique de leurs usagers. Les ordinateurs vont régénérer le corps: dans sa naïveté, le message relève d'un mythe du corps en cours de formation. La recherche universitaire se penche sur cette thématique. En 1985, la Socialist Review publie le célèbre «Cyborg Manifesto » de Donna Haraway qui proclame haut et fort le «besoin de régénération» des citoyens du monde technologique. Les ordinateurs sont des «machines de lumière » qui poussent les possibilités de reconstitution de l'humain jusqu'au seuil du «rêve utopique $^{8} »$.

Mais déjà l'utopie projette son ombre. C'est justement à la moitié des années 1980 que les virus informatiques sont découverts ${ }^{9}$. Les premières alertes aux logiciels malveillants rappellent que les ordinateurs peuvent aussi être vus comme des objets contaminants, virulents. Classiquement, la nouveauté technologique engendre des réactions de crainte, mais les anxiétés de contamination informatique tiennent leur place dans une trame d'appréhensions plus spécifiquement liées au corps. La peur des logiciels-virus prend une résonance toute particulière dans le contexte de l'explosion de l'épidémie de sida de ces mêmes années.

Les nouveaux usages technologiques, souvent à la limite de la légalité, tel le partage de fichiers numériques, sont classés parmi les «pratiques à risque», associés à la souillure, à la maladie et à la contagion. Autour de 1988, quand l'alarme sida bat son plein, la presse adopte une sémantique médicale pour parler du piratage informatique $^{10}$. Auparavant, les métaphores les plus communément empruntées étaient de nature militaire: les hackers «attaquaient» et «envahissaient» les ordinateurs des entreprises pour les «espion-

7. Pour une analyse complète du spot Apple 1984 et de sa signification dans la culture des ordinateurs des années 1980, voir Owen W. Linzmayer, Apple Confidential: The Real Story of Apple Computer Inc., San Francisco, CA, No Starch Press, 1999; Ted Friedman, Electric Dreams: Computers in American Culture, New York, New York University Press, 2005.

8. Voir, dans ce même dossier, la discussion de Delphine Gardey sur la portée historique du texte de Donna Haraway, «A Cyborg Manifesto».

9. La première définition des virus informatiques est contenue dans Frederick B. Cohen "Computer Viruses: Theory and Experiments", dans Proceedings of the 7th DoD/NBS Computer Security Conference, Gaithersburg, National Bureau of Standards, 1984, p. 240-263.

10. Ces résultats se basent sur une analyse textuelle d'un corpus de 654 articles parus dans la presse internationale en langue anglaise entre le $1^{\text {er }}$ janvier 1985 et le $1^{\text {er }}$ janvier 1989 (service LexisNexis, mots clés hacker, computer crime et hacking). 
ner» ou exploiter leurs «vulnérabilités ». Aussi les médias privilégiaient des histoires dans lesquelles les malfaiteurs étaient des jeunes fervents de «jeux de guerre» et les victimes, typiquement, des agences militaires de sécurité nationale. Après 1988, cette terminologie martiale est peu à peu abandonnée. Les logiciels nocifs deviennent alors des «maladies» qui requièrent la «médicalisation» des ordinateurs et l'administration de «soins" antivirus dont les noms commerciaux ne laissaient pas d'espace à l'imagination: "Généraliste des données»(Data Physician), «Contrepoison»(AntiDote), «Vaccin antigrippal»(Flushot)... La contamination technologique prend parfois le déguisement d'une maladie sexuellement transmissible, tandis que les peurs concernant la dimension organique se font miroir de celles concernant la pratique informatique.

Les pratiques informatiques accompagnent ces représentations. En contournant le contrôle opéré par les professionnels de la biomédecine (cliniciens, instances de la recherche scientifique, industries pharmaceutiques, décideurs publics, etc.), des informaticiens militants entreprennent de mettre en réseau les patients VIH.sida. Un important mouvement social de contestation de la médecine institutionnelle, au sein duquel est attestée l'utilisation massive de microordinateurs, se met en place et commence rapidement à prendre une dimension transnationale. Grâce à la télématique, au cœur de ces "réseaux de désobéissance civile électronique ${ }^{11}$ ", un ensemble de revendications et de conflits politiques jusque-là dispersés peut se composer dans une ébauche d'action unitaire. Des particuliers, des praticiens hétérodoxes, des malades et des sujets disparates partagent un même dessein - promouvoir la prise en charge thérapeutique assistée par ordinateur.

Derrière des initiatives fondatrices, tel le bulletin d'information Aids Treatment News ou le centre de documentation électronique Critical Path, se cachent des pionniers des communautés télématiques $^{12}$. Une profusion de forums et de bases de données en ligne s'offre aux malades du sida et à leurs proches. Plusieurs messageries électroniques - tels AidsInfo, Newsbase Computer ou le Gay and Lesbian Electronic Access Network - mettent à disposition de leur public des articles sur la prévention et les nouveaux traitements. Le Congrès de l'Oms de Stockholm de 1988 est suivi via ordinateur par des usagers disséminés partout dans le monde ${ }^{13}$.

11. La locution a été créée à la fin des années 1980 par le collectif d'artistes hacker Critical Art Ensemble à l'occasion d'un projet commun avec Act Up. Critical Art Ensemble, Electronic Civil Disobedience and Other Unpopular Ideas, Brooklyn, Autonomedia, 1996.

12. Le créateur de Aids Treatment News, John S. James, avait été l'animateur de la première communauté électronique virtuelle, CommuniTree. Le directeur de Critical Path, Kiyoshi Kuromiya, était un personnage historique du milieu d'activistes électroniques de Philadelphie.

13. John S. James, "Aids Computer Conference from Stockholm", Aids Treatment News, $\mathrm{n}^{0} 57,20$ mai 1988. 
Les milieux de passionnés d'ordinateurs soutiennent la création d'associations clandestines d'acheteurs se procurant des médicaments hors marché (undergound buyers' clubs) et divulguant des informations médicales en dépit des lois sur la protection de la propriété intellectuelle. Surtout, ils excellent dans la coordination politique des groupes de défense des malades du sida. Dans la controverse sur les essais cliniques de la Food and Drug Administration (FDA, la haute autorité américaine autorisant la mise sur le marché de nouveaux médicaments), ils dirigent une importante campagne pour la déréglementation des essais cliniques des nouveaux traitements contre le sida. Entamée en 1987, celle-ci aboutit à l'assouplissement des protocoles en "double-aveugle», qui avaient, jusque-là, constitué une procédure standard pour la recherche médicale internationale ${ }^{14}$.

Grâce à la micro-informatique, partout les malades prennent la parole et interpellent directement les responsables de santé publique. Les usages numériques aident à promouvoir des pratiques thérapeutiques alternatives et des savoirs critiques vis-à-vis de la biomédecine contemporaine. La philosophie qui anime les réseaux communautaires est celle du «malade agissant» qui se sert des réseaux télématiques comme de ses maîtres outils. Une nouvelle subjectivité politique ambitionne de questionner le pouvoir clinique et ses modalités de pensée hiérarchisées, afin de se réapproprier le corps dans un but de participation directe à la vie sociale.

En arrière-plan de l'action des réseaux d'activistes pour les droits des séropositifs, on aperçoit un désir de «porter la contestation» au sein même de la vision médicale du corps. Les collectifs de microinformaticiens ont pour but de distribuer le pouvoir de soin et d'entretien du corps en multipliant le nombre des sujets légitimés à se prononcer sur les modalités de sa prise en charge. Dans son élan utopique, la culture du numérique aspire à s'imposer en institution savante de fait.

\section{Virtualités thérapeutiques}

Néanmoins, les bases de données en ligne et les bulletins électroniques de ces années ne sont pas des réceptacles d'avis scientifiques unifiés, mais plutôt des lieux de rencontre pour une pluralité d'opinions reflétant des intérêts, des priorités et des façons diverses de vivre le corps. Si le savoir biomédical se base sur une vision unitaire

14. Pour une reconstruction de la controverse sur les essais cliniques de la FDA, ainsi que de l'usage de technologies électroniques dans des buts politiquement progressistes dans le cadre des revendications pour la mise en place d'un système "d'essais communautaires ", voir Paula A. Treischler, "How to Have Theory in an Epidemic: The Evolution of Aids Treatment Activism", dans Constance Penley et Andrew Ross (eds), Technoculture, Minneapolis, University of Minnesota Press, 1991, p. 57-106. 
de la nature humaine et de la corporéité, les réseaux militants permettent aux spécificités culturelles (origine ethnique, genre, style de vie) d'être représentées activement.

L'élément fédérateur est, encore une fois, la nature chimérique du corps interfacé avec la machine à calculer. Par antithèse à la virulence ambiante, l'imaginaire social du corps régénérable à l'aide des technologies numériques est traversé par un besoin de pureté, de transparence, de filtration des humeurs et des fluides. C'est au tournant des années 1990, avec l'arrivée de la vague technologique des soi-disant «réalités virtuelles » que l'évocation de corps diaphanes et légers, évoluant dans un cyberespace d'information pure, s'intensifie. Des «gants de données»(datagloves) et les «lunettes stéréoscopiques » (eyegoggles) donnent à l'usager l'impression d'être immergé dans une réalité alternative, où habitent des corps intangibles, mais combien vivants. À l'écran, des interfaces virtuelles permettent de représenter des membres (des mains, des visages, etc.) ou des anatomies complètes qui interagissent avec des objets 3D.

C'est surtout en Californie du Nord qu'est élaboré le mythe du corps virtuel dématérialisé. Jadis la patrie de la contre-culture hippie, ensuite bassin d'élevage des jeunes talents de la Silicon Valley, la baie de San Francisco est désormais le centre nodal de la mouvance de la «psychédélie cybernétique» (cyberdelia) - un curieux mélange d'ardeurs techno-visionnaires et de pensée New Age ${ }^{15}$. C'est en 1990, dans les pages de l'influent magazine californien Mondo 2000, que le mythe fait sa première apparition dans le compte rendu de la première séance de réalité virtuelle d'un usager d'exception: le parolier de rock psychédélique et militant pour la liberté d'expression en ligne, John Perry Barlow. Revêtu de gants et de lunettes numériques, allongé dans un fauteuil, son "corps matériel " affiche les marques de la maladie, de la raideur, de la régression vers le stade infantile. Mais les faiblesses de ce physique diminué et souffrant laissent vite la place à une euphorie aérienne. Dans son monde de synthèse, l'usager peut danser, sauter, se déplacer dans une ambiance de parc de loisirs. La mise en transcendance technologique du corps restitue le sens d'une stimulation sensorielle totale, que l'auteur n'hésite pas de qualifier de "chatouillement cosmique» (cosmic titillation ${ }^{16}$ ).

Il serait difficile de lire dans cette frénésie vitaliste une perte ou un oubli du corps, comme le voudraient certains commentateurs ${ }^{17}$.

15. Sur le milieu «cybedélique » californien des années 1990, voir Mark Dery, Escape Velocity: Cyberculture at the End of the Century, New York, Grove Press, 1996; Erik Davis, Techgnosis: Myth, Magic + Mysticism in the Age of Information, New York, Harmony Books, 1998.

16. John Perry Barlow, "Being in Nothingness: Virtual Reality and the Pioneers of Cyberspace", Mondo 2000, no 2, été 1990, p. 34-43.

17. Voir à ce sujet Lucien Sfez, la Santé parfaite: critique d'une nouvelle utopie, Paris, Le Seuil, 1995; Slavoj Zizek, "From Virtual Reality to the Virtualization of Reality", dans Timothy 
Certes, dans le virtuel, l'embarras des tissus vivants, les alarmes liées à l'interne inconnaissable et aux cavités du corps sont évacués à la faveur d'une physionomie vide et éthérée, où les octets remplacent la chair. Manœuvre d'escamotage imaginaire des peurs de contamination des années sida, cette envie de désincarnation ne semble pas animée par une disposition ascétique à la renonciation de la dimension corporelle. C'est justement un souci du corps et de sa récupération dans un moment de crise de confiance à l'égard des savoirs médicaux légitimement préposés à sa défense qui est colporté par les enthousiastes du virtuel des années 1990. La dématérialisation imaginaire de l'organisme s'inscrit dans le droit fil de la critique de la vision clinique du corps commencée dans la décennie précédente.

Le mythe s'accorde aussi aux pratiques de soin alternatives - les médecines douces, les remèdes traditionnels et l'homéopathie - que les adeptes californiens du New Age à la sauce électronique mélangent avec les dernières trouvailles technologiques. À Big Sur, à quelques centaines de kilomètres à peine de la Silicon Valley, se trouve le siège de l'Esalen Institute - le foyer du Mouvement pour le potentiel humain prônant la nécessité de conjuguer les médecines traditionnelles avec les acquis de la télématique afin d'aller vers le corps du futur $^{18}$. Les systèmes de réalité virtuelle se marient alors avec les méthodes de biofeedback (rétrocontrôle des fonctions organiques grâce à l'utilisation d'appareils numériques) ou de guided imagery (visualisation d'images positives de guérison à l'aide d'ordinateurs). Des pages des revues d'informatique, l'archétype du corps translucide s'élevant au-dessus de la matière opaque migre dans les manuels d'energy healing. La pleine expression de «l'énergie vitale» ne serait possible qu'à condition de restaurer l'équilibre entre le corps et son environnement - et dans un environnement saturé par les médias numériques, le corps aussi se doit de devenir de l'information pure.

Un idéal holistique de santé, dépassant la seule dimension organique du corps, trouve dans les technologies virtuelles son accomplissement. Les expectatives de guérison équilibrée et harmonieuse se conjuguent alors avec le désir de prise en charge autonome du corps, avec la liberté de choix thérapeutique qui a déjà animé les réseaux de désobéissance électronique des années 1980. La santé ne se borne plus à un état passif d'absence de sensations négatives. Le mythe du corps virtuel incite l'usager à la recherche d'un bien-être actif, d'un «mieux-être ${ }^{19} »$. Dans ce cadre, le simple «rétablisse-

Druckrey (ed.), Electronic Culture: Technology and Visual Representation, New York, Aperture, 1996, p. 290-295; David Le Breton, l'Adieu au corps, Paris, Métailié, 1999.

18. Michael Murphy, The Future of the Body: Explorations into the Further Evolution of Human Nature, Los Angeles, J. P. Tarcher, 1992.

19. Pour une définition du mieux-être, voir Georges Vigarello, le Sain et le malsain. Santé et mieux-être depuis le Moyen Âge, Paris, Le Seuil, 1993. 
ment » de la santé visé par la médecine allopathique - la récupération de valeurs normales sur le plan chimique, métabolique ou physiologique - devient insignifiant.

\section{Recul de l'utopie et appropriation médicale des technologies numériques}

La propagation de ces imaginaires sociaux du corps technologique finit par avoir des conséquences inattendues pour le domaine biomédical. Dans le but de regagner le terrain perdu à la suite des controverses entourant l'alarme sida, les professionnels de la santé se rapprochent progressivement du domaine de l'informatique. Entre 1992 et 1993 nombre de colloques scientifiques commencent à présenter des utilisations de plus en plus importantes de dispositifs numériques interactifs dans des domaines disparates. Dans la chirurgie miniinvasive, en manipulant sur un écran une restitution tridimensionnelle d'un organe, le chirurgien actionne un robot qui exécute sur le patient les tâches commandées ${ }^{20}$. Dans l'imagerie médicale, sont désormais disponibles des résonances magnétiques, des échographies ou des électrocardiogrammes tridimensionnels numériques beaucoup plus complets que leurs antécédents analogiques ${ }^{21}$. La formation médicale, la médecine de réadaptation, ou la télémédecine, aussi, doivent beaucoup aux interfaces immersives et à la communication en ligne ${ }^{22}$.

La biomédecine s'invite, pour ainsi dire, au banquet du virtuel. Un nouveau syncrétisme entre acteurs du complexe médico-industriel international et passionnés d'informatique semble se profiler, sur le plan culturel comme sur le plan social. Parmi les conférenciers des colloques "Medicine Meets Virtual Reality" ou "Virtual Reality and Persons with Disabilities" figurent autant des écrivains de sciencefiction et des pionniers des technologies numériques, que des biochimistes ou des barons de la médecine clinique - le tout sous l'égide de puissantes industries pharmaceutiques.

Le discours utopique est approprié par les professionnels de la biomédecine pour mieux désamorcer les extravagances Nouvel Âge et les contestations des réseaux électroniques des années précédentes.

20. Ferenc A. Jolesz et Faina Shtern, "The Operating Room of the Future: Report of the National Cancer Institute Workshop", Investigative Radiology, vol. 27, no 4, 1992, p. 326-328.

21. Michael W. Vannier, Randall E. Yates et Jennifer J. Whitestone (eds), Proceedings from the Working Group on Whole-Body, Three-Dimensional Electronic Imaging of the Human Body, Wright-Patterson AFB, CsERIAC, 1993.

22. Andrew F. Payer, J. Mark Voss et Laurie Spargue, "Development of Virtual Environments for Medical Education and Training", dans Proceedings of 1993 Conference on Intelligent Computer-Aided Training and Virtual Environment Technology, ICAT-VET, vol. 2, Houston, Johnson Space Center, NASA, 1993, p. 69. 
Les cliniciens qui font mine d'être gagnés à la cause du virtuel présagent en réalité l'avènement d'un «nouvel ordre mondial médical ${ }^{23}$ " où les technologies cesseraient d'être de simples machines au service de la fantaisie humaine pour redevenir des outils d'assainissement et de prophylaxie ${ }^{24}$. Au cœur des applications médicales immersives, le corps numérique ne flotte plus librement dans «l'océan astral des données». Dans les interfaces de médecine virtuelle, il se retrouve cloué à un bloc opératoire, entouré de praticiens en gants de données et visiocasques. Ou bien il gît sur un lit, couronné par les images informatisées de ses fichiers cliniques.

Ce processus - iconographique autant que technique - de réinscription du corps dans la normation médicale se poursuit après l'explosion de popularité du World Wide Web, vers la moitié des années 1990. Le remarquable succès du Visible Human Project y contribue pour beaucoup: en 1994, la National Library of Medicine des ÉtatsUnis met en ligne les tomographies computérisées de deux corps humains complets - un condamné à mort texan et une femme anonyme dont le cadavre avait été «donné à la science par son mari ${ }^{25}$ ». Cet atlas anatomique de nouveau type permet la construction de modèles humains 3D à des fins didactiques et diagnostiques. Mais ses formats de diffusion (cédéroms, logiciels et sites Web accessibles gratuitement) ne laissent pas de doute quant au public visé: avant tout les internautes et informaticiens militants.

Mais l'accessibilité télématique ne constitue qu'un appât pour les usagers du Web. La transposition numérique du corps humain n'est plus associée à un geste d'émancipation. Le Visible Human Project opère une régression vers le primat de "l'anatomie pré-numérique ", empreinte de "matérialisme de base ", hostile à toute vision alternative $^{26}$. Les corps scannérisés portent les marques fatales de leur encadrement autoritaire: la domination sexuelle du sujet féminin (pour qui le consentement à la donation est revenu à son époux); l'enfermement carcéral du sujet masculin (dont le cadavre a été octroyé par la prison où il était détenu). Cette démarche de dépropriation posthume assimile tendanciellement le corps de chaque internaute à

23. Richard M. Satava, "Virtual Reality and the New World Order of Medicine", Virtual Reality Systems, vol. 1, nº 3, 1994, p. 6

24. Amal Kumar Naj, "Virtual Reality Isn't a Fantasy for Surgeons", The Wall Street Journal, 3 mars 1993; Louis B. Rosenberg, "Medical Applications of Virtual Reality", Virtual Reality Systems, op. cit., p. 48-50.

25. Simon Baatz, "Medical Science and Medical Informatics: The Visible Human Project 1986-2000", dans W. Boyd Rayward et Mary Ellen Bowden (eds), The History and Heritage of Scientific and Technological Information Systems. Proceedings of the 2002 Conference, Medford, Information Today, 2004, p. 110-117.

26. Eugene Thacker, "Lacerations: The Visible Human Project, Impossible Anatomies, and the Loss of Corporeal Comprehension", CultureMachine, $\mathrm{n}^{0}$ 3, 2001, www.culturemachine. net/index.php/cm/article/viewArticle/293/278 [dernier accès 26 mai 2008]. 
celui de l'assassin exécuté ou de la femme légalement assujettie ${ }^{27}$. Les codes esthétiques du corps virtuel - sa translucidité, sa légèretésont aussi renversés. Le regard des utilisateurs se laisse alors capturer par les épidermes meurtris, par les physionomies «inquiétantes ", «intolérables », « abjectes ${ }^{28}$ » des corps en réseau.

La normalisation de l'imaginaire numérique s'exprime aussi dans les efforts déployés par les professionnels de la santé pour contrecarrer la diffusion d'informations scientifiques en ligne. Le Web se transforme vite en une mine inépuisable d'études et d'avis médicaux en libre accès. C'est pourquoi les thérapeutes ne se lassent pas d'exprimer leur préoccupation vis-à-vis du contournement de la médiation médicale de la part des patients usagers de l'internet. La mise entre parenthèses de la relation soignante en face à face comporte le risque croissant de se perdre dans un marasme de chiffres et d'images numérisées ${ }^{29}$. Nombre d'enquêtes pointent du doigt le danger que cet éparpillement du savoir médical sur l'internet peut représenter pour la santé publique. Les «médecins s'aperçoivent que les patients sont en train de mettre en question leur autorité »; ils mettent désormais en garde contre le «préjudice à l'activité soignante porté par la détérioration évidente de la relation entre patient et médecin ${ }^{30} »$. Abandonnés à eux-mêmes, les usagers ne vont-ils pas devenir des «cybercondriaques », des malades imaginaires numériques?

Soulignons-le: ce ne sont plus, comme avant, les applications médicales des produits informatiques qui sont mises en discussion par les thérapeutes, mais les potentiels effets pathogènes de l'accès non discipliné, non corroboré par des professionnels de la santé, aux technologies. Pour le reste, les vieux a priori des médecins vis-à-vis du numérique ont été balayés par la banalisation de la pratique télématique suivant le boom de l'internet. D'autant plus que, à la fin de la décennie 1990, l'implication de la culture technologique s'avère décisive pour le développement d'une nouvelle génération de produits et de prestations médicales, associée cette fois-ci aux biotechnologies.

Après le succès des premières expériences de clonage (1997) et de séquençage du génome humain (2000), se consolide l'impression que la bio-informatique - le sous-domaine du biotech qui applique des techniques computationnelles aux systèmes biologiques et aux orga-

27. Lisa Cartwright, "The Visible Man: The Male Criminal Subject As Biomedical Norm", dans Jennifer Terry et Melodie Calvert (eds), Processed Lives: Gender and Technology in Everyday Life, Londres, Routledge, 1997, p. 123-138.

28. Catherine Waldby, "Revenants: The Visible Human Project and the Digital Uncanny", Body and Society, vol. 3, $\mathrm{n}^{\circ} 1,1996, \mathrm{p} .1-16$.

29. Didier Sicard, la Médecine sans corps : une nouvelle réflexion éthique, Paris, Plon, 2002.

30. Elizabeth Murray, Bernard Lo, Lance Pollack et al., "The Impact of Health Information on the Internet on Health Care and the Physician-Patient Relationship: National US Survey among 1,050 US Physicians", Journal of Medical Internet Research, vol. 5, nº3, 2003, e 17, http://www.jmir.org/2003/3/e17/ [dernier accès 22 mai 2008]. 
nismes vivants - représente une issue logique de la révolution numérique des années précédentes. Les chercheurs de Celera Genomics, l'entreprise qui est derrière le succès de l'initiative pour le génome humain, s'inspirent à l'éthique hacker du partage d'information ${ }^{31}$ et posent en héritiers désignés des amateurs d'électronique des années 1980. La mise en commun des résultats et des bases de données comme GenBank, est la preuve de l'efficacité de l'esprit de collaboration répandu dans les communautés télématiques. Le magazine Wired, qui avait jusque-là jugé avec sévérité la génétique, présente désormais le séquençage comme une percée technologique faisant «apparaître la révolution électronique comme un feu de paille ${ }^{32}$ ». Mais les réseaux de désobéissance électroniques ont-ils encore un rôle à jouer dans le nouveau contexte biotech? À en croire Wired, une multitude de «savants citoyens", sans affiliation institutionnelle, serait en train d'accomplir les exploits génomiques de demain:

Tu peux littéralement être un chasseur de gènes dans l'intimité de ta maison, la nuit, pendant que tes enfants dorment dans leurs lits ${ }^{33}$.

La bio-informatique s'affiche au cœur des foyers, comme l'avait fait la micro-informatique presque vingt ans auparavant.

Mais on est loin, désormais, des contestations télématiques des années 1980. Très vite, il faut se rendre à l'évidence que les biologistes computationnels ne sont pas des informaticiens militants, mais avant tout des partisans de l'ordre biomédical ${ }^{34}$. La culture du numérique est mise au service des sciences de la santé. Le séquençage du génome humain représente surtout un nouveau début pour la médecine prédictive du troisième millénaire ${ }^{35}$. Grâce aux progrès liés aux recherches sur les cellules souches, la promesse d'une «médecine régénératrice» devient réalite ${ }^{36}$. Le clonage total ou partiel des organes humains et la reproduction assistée représentent une injection de confiance pour la biomédecine, qui désormais peut se poser comme but rien d'autre que «la poursuite du bonheur» en allant «au-delà de la thérapeutique ${ }^{37}$ ».

Dans un renversement des prémisses mêmes de la culture du numérique, les nouvelles technologies se retrouvent dérobées de leur

\footnotetext{
31. Pour une étude de l'éthique hacker, voir Pekka Himanen, l'Éthique hacker, Paris, Exils, 2001.

32. Charles Platt, "Evolution Revolution", Wired, vol. 5, nº 1, janvier 1997.

33. Sara Solovitch, "The Citizen Scientists", Wired, vol. 9, no 9, septembre 2001.

34. C. Platt, "Evolution Revolution", art. cité.

35. Charles Delisi, "Genomes: 15 Years Later a Perspective by Charles DeLisi, HgP Pioneer", Human Genome News, vol. 11, nº 3-4, 2001, http://www.ornl.gov/sci/techresources/Hu man_Genome/publicat/hgn/v1ln3/05delisi.shtml [dernier accès 15 mai 2008].

36. Fred H. Gage, "Stem Cells at the Dawn of the 21st Century", dans Proceedings of the National Academy of Sciences of the United States of America. Regenerative Medicine, vol. 100, suppl. 1, 2003, p. 11817-11818.

37. President's Council on Bioethics, Beyond Therapy. Biotechnology and the Pursuit of Happiness, New York, Harper Collins, 2003.
} 
impulsion utopique et absorbées dans l'orbite de la big science des savants en combinaison blanche. Les passions technophiles s'estompent, tandis que les milieux proches de la culture numérique s'empressent de liquider les approches alternatives aux soins qui avaient eu une si grande part dans l'édification des discours numériques du corps. Les réseaux électroniques pour la défense des droits des malades du sida se défont, et les thérapies holistiques endurent une remise en discussion au fur et à mesure que leur absorption dans les institutions de santé publique se fait ostensible ${ }^{38}$. Pris dans les mailles du biotech, l'imaginaire utopique de la culture des ordinateurs se résigne à la simple adéquation du corps à la norme du «génétiquement correct »- ce qui, comme ne manque pas de le souligner Jeremy Rifkin, ne va pas sans évoquer le risque d'une version ajournée de l'eugénisme du siècle passé ${ }^{39}$.

\section{Que reste-t-il des utopies numériques?}

La restitution présentée dans les pages qui précèdent est cohérente avec un programme théorique, faisant ses premiers pas dans les sciences sociales, de constitution d'une historiographie du phénomène numérique ${ }^{40}$. Manifestement, entre le début des années 1980 et la fin de la décennie suivante, la corporéité a vécu un "moment cyber». Dans cet intervalle historique, une multitude d'usagers a aménagé un dispositif culturel et sociopolitique capable de véhiculer les attentes liées à la corporéité. Cette utopie doit être aujourd'hui reconnue comme un phénomène conjoncturel, historiquement situé. La montée de l'imaginaire du corps régénéré par les technologies informatiques, un corps idéal accessible au tout-venant, a été la conséquence d'un ensemble de circonstances précises. Le but a été ici d'éclairer l'une de ces circonstances, la crise de confiance vis-à-vis des institutions médicales. C'est face à l'alarme sida - «fléau du nouveau millénaire », contagion déshonorante pour laquelle initialement il n’y a aucune solution thérapeutique ${ }^{41}$ - que la cyberculture conçoit le rêve d'un corps améliorable d'un clic de souris. Un corps fait pour la convivialité et la jouissance, symboliquement éloigné de la mort et de la maladie.

38. Barker Bausell, Snake Oil Science. The Truth about Complementary and Alternative Medicine, New York, Oxford University Press, 2007.

39. Jeremy Rifkin, The Biotech Century: Harnessing the Gene and Remaking the World, New York, J. P. Tarcher/Putnam, 1998.

40. Jonathan Sterne, "The Historiography of Cyberculture", dans David Silver et Adriana Massanari (eds), Critical Cyberculture Studies, New York/Londres, New York University Press, 2006, p. 17-28.

41. Bernard Paillard, l'Épidémie. Carnets d'un sociologue, Paris, Stock, 1994. 
Mais notre analyse nous conduit finalement à constater que cette confrontation entre l'imaginaire cyber et le savoir médical a une issue paradoxale. Les mythes du corps virtuel finissent par constituer un apport déterminant pour la science médicale même. Il faut bien l'admettre: somme toute, c'est la biomédecine qui a remporté la mise. Non seulement elle a surmonté les difficultés des années 1980 et 1990, mais elle a fini par détourner les usages technologiques et leurs promesses. Toutefois, on ne peut pas parler de défaite de la culture du numérique. Jamais la pénétration des nouveaux médias dans le tissu social n'a été plus évidente qu'aujourd'hui - avec l'omniprésence des réseaux mobiles et l'impact sur le quotidien du Web 2.0., avec ses blogs et ses sites de networking social.

L'utopie informatique du corps disparaît, mais les usages restent, et ils changent la profession médicale de l'intérieur. Dans les toutes dernières années, les professionnels de la santé ont voulu «créer des complicités » entre la médecine et les nouvelles technologies. Partout dans le monde, l'imagerie médicale numérique la plus sophistiquée s'est banalisée, les cliniciens font figure de fervents du Web collaboratif ${ }^{42}$, les hôpitaux se dotent de services de consultation en ligne, les sites internet à vocation médicale se multiplient d'une manière exponentielle ${ }^{43}$. Certes, la relation soignante est encore centrée sur l'autorité scientifique du médecin, à laquelle le malade se soumet. Et la rencontre en face à face avec le patient demeure indispensable pour éviter de se perdre dans un capharnaüm de chiffres et d'images numérisées ${ }^{44}$. Mais les ordinateurs connectés au Réseau sont devenus des outils quasi symboliques de la profession médicale, comme autrefois les tubes et les seringues.

Ce qui avait commencé comme un conflit entre les professionnels de la santé et le monde des ordinateurs, des hackers et des virus informatiques, se termine avec une assimilation du numérique par la recherche médicale. Les utopies du corps des «enfants de l'ordinateur » sont finalement à l'origine du renouveau du complexe médicoindustriel qu'elles cherchaient pourtant à mettre en question.

Antonio A. Casilli

42. Maged N. Kamel Boulos, Inocencio Maramba et Steve Wheeler, "Wikis, Blogs and Podcasts. A New Generation of Web-based Tools for Virtual Collaborative Clinical Practice and Education", BMC Medical Education, vol. 6, no 41, http://www.biomedcentral.com/ 1472-6920/ 6/41 [dernier accès 22 mai 2008].

43. Elizabeth Sillence, Pam Briggs, Peter Richard Harris et Lesley Fishwick, "How Do Patients Evaluate and Make Use of Online Health Information?", Social Science \& Medicine, vol. 64, no 9, mai 2007, p. 1853-1862.

44. Clement J. Mcdonald, J. Marc Overhage, Burke W. Mamlin, Paul D. Dexter et William M. Tierney, "Physicians, Information Technology, and Health Care Systems. A Journey, not a Destination", Journal of American Medical Information Association, vol. 11, n 2, 2004, p. 121-124. 